\title{
A new white clover cultivar of potential importance for upland areas
}

\author{
R. P. Collins and M. Fothergill \\ Institute of Grassland and Environmental Research, Aberystwyth
}

\section{Introduction}

It has been well documented that white clover grows more slowly at low temperatures than perennial ryegrass (its usual companion species in the United Kingdom), and is placed at a competitive disadvantage early in the growing season. Consequently, white clover may not be present in sufficient quantities in cold upland areas at a time when animal requirements are highest.

The yield of white clover in mixed swards is related to the quantity and quality of stolon material surviving the winter (Collins, Glendining and Rhodes, 1991). Winter survival and growth at low temperatures have traditionally been regarded as being negatively correlated characteristics. However, a new medium-leaved clover cultivar, Ac51, has been developed at the Institute of Grassland and Environmental Research (IGER) which possesses improved winter survival of stolon coupled with enhanced spring growth.

\section{Material and methods}

Ac51 was developed from white clover populations collected in mountainous areas of Switzerland.

\section{Experiment 1}

White clover cultivars Ac51 and Grasslands Huia were grown in binary mixtures with perennial ryegrass $\mathrm{cv}$. S23. The experiment was established at a site $30 \mathrm{~m}$ above sea level, and was designed as a complete randomized block incorporating four replications. Each individual plot was $2 \times 2 \mathrm{~m}$. Detailed measurements of stolon length and weight were made during the winter in 2 years successively by removing a $15 \times 15 \mathrm{~cm}$ turf from each plot and subsampling the live stolon material (Table 1). In addition, stolon samples were removed from the field in January 1990 and assessed for their cold tolerance using an ethylene glycol 'cold tank' (Fuller and Eagles, 1981). This freezing test gave values of $\mathrm{LD}_{50}$ - the temperature at which $50 \%$ of the samples were killed (Table 2).
Table 1 Amount of stolon surviving in white clover cultivars after winter in 2 years (with LSD at $5 \%$ level)

\begin{tabular}{llrr}
\hline \hline & \multicolumn{2}{l}{ Clover cultivar } & \\
\cline { 2 - 3 } & Huia & Ac51 & LSD \\
\hline Year 1 $(1985 / 86)$ & & & \\
Stolon length $\left(\mathrm{m} / \mathrm{m}^{2}\right)$ & 45.8 & 60.4 & $15 \cdot 8$ \\
Stolon weight $\left(\mathrm{g} / \mathrm{m}^{2}\right)$ & 34.6 & 60.9 & 12.7 \\
Year 2 $(1986 / 87)$ & & & \\
Stolon length $\left(\mathrm{m} / \mathrm{m}^{2}\right)$ & 51.4 & 111.5 & 7.5 \\
Stolon weight $\left(\mathrm{g} / \mathrm{m}^{2}\right)$ & 28.7 & 105.7 & $22-3$ \\
\hline \hline
\end{tabular}

Table 2 Values of $\mathrm{LD}_{50}$ for white clover stolon samples

\begin{tabular}{lll}
\hline \hline Clover cultivar & LD $_{50}$ & s.e. \\
\hline Huia & -4.27 & 0.27 \\
Ac51 & -6.22 & 0.23 \\
\hline
\end{tabular}

Experiment 2

Two white clover cultivars (Huia and Ac51) were sown with perennial ryegrass (cv. Talbot) in 1989 at a site $310 \mathrm{~m}$ above sea level. Four replicates of each cultivar were included under two grazing managements in a split-plot design. Petiole length, leaf dry weight and leaf area were measured by randomly selecting 10 leaves from each plot on 4 April 1992 (Table 3).

\section{Results and discussion}

The results in Table 1 show that although both clover cultivars lost stolon material during the winter, the reduction in stolon length and weight was less marked in Ac51 than in Grasslands Huia in both years.

Table 2 shows that stolons of Ac51 were more cold tolerant than those in Huia, which confirms the results of the field measurements. 
Table 3 Morphological characters of white clover in April 1992 (mean of two grazing managements)

\begin{tabular}{lccc}
\hline \hline & $\begin{array}{c}\text { Petiole } \\
\text { length } \\
(\mathrm{cm})\end{array}$ & $\begin{array}{c}\text { Leaf } \\
\text { dry weight } \\
(\mathrm{mg})\end{array}$ & $\begin{array}{c}\text { Leaf area } \\
\left(\mathrm{cm}^{2}\right)\end{array}$ \\
\hline Huia & 2.57 & 2.23 & 1.74 \\
Ac51 & 3.65 & 7.75 & 2.50 \\
\hline \hline
\end{tabular}

The results in Table 3 show that Ac51 possessed significantly longer petioles, greater leaf weight and larger leaf area than the control variety, Grasslands
Huia. The agronomic consequence of the combination of these characters is the potential for improved clover contribution to herbage production in the spring. This would be of particular relevance in the harsh environment of the less-favoured areas of upland Britain.

\section{References}

Collins, R. P., Glendining, M. J. and Rhodes, I. 1991. The relationships between stolon characteristics, winter survival and annual yields in white clover (Trifolium repens L.). Grass and Forage Science 46: 51-61.

Fuller, M. P. and Eagles, C. F. 1981. Effect of temperature on cold-dehardening of Lolium perenne L. seedlings. Journal of Agricultural Science, Cambridge 96: 55-59. 